\title{
Composição bromatológica e dinâmica de fermentação da silagem de jaca
}

\section{Chemical composition and fermentation dynamics of jackfruit silage}

\author{
João Ricardo Rebouças Dórea루 Luiz Gustavo Ribeiro Pereira²; \\ Alexandre Lima Ferreira ${ }^{3}$; Thiago Carvalho da Silva ${ }^{4}$; \\ José Augusto Gomes Azevedo ${ }^{5}$; Vinícius Nunes de Gouvêa ${ }^{1}$; \\ André Luiz Custódio Franco ${ }^{6 *}$
}

\begin{abstract}
Resumo
Avaliaram-se os efeitos da inclusão de fubá de milho (5\%) e uréia (1\%) sobre a composição bromatológica e o perfil fermentativo da silagem de jaca, utilizando-se delineamento experimental inteiramente casualisado em arranjo fatorial $3 \times 7$ (tratamentos $\mathrm{x}$ dia de abertura), com duas repetições. Foram utilizados silos experimentais de PVC, $10 \mathrm{~cm}$ de diâmetros x $40 \mathrm{~cm}$ de comprimento. A abertura dos silos seguida da avaliação da composição bromatológica e do perfil fermentativo da silagem ocorreu aos $1,3,5,7,14,28$ e 56 dias após a ensilagem. Os teores de matéria seca (MS) e proteína bruta (PB) foram elevados significativamente $(\mathrm{P}<0,05)$ com a adição de $5 \%$ de milho e $1 \%$ de uréia, respectivamente. $\mathrm{O}$ $\mathrm{pH}$ encontrado em todos os tratamentos foi considerado ideal para silagens de boa qualidade. A adição de uréia aumentou significativamente $(\mathrm{P}<0,05)$ os valores de nitrogênio amoniacal $(\mathrm{N}-\mathrm{NH} 3 / \mathrm{NT})$. A adição de $1 \%$ uréia funcionou como álcali na parede celular do material ensilado, demonstrado pela redução nos teores das frações fibrosas. A jaca apresenta potencial de conservação na forma de silagem e a utilização de milho e uréia como aditivos melhora o perfil fermentativo e a qualidade da silagem.

Palavras-chave: Aditivo, alimento alternativo, Artocarpus heterophyllus, fermentação
\end{abstract}

\begin{abstract}
It was evaluated the effect of adding corn meal (5\%) and urea (1\%) in the chemical composition and fermentation characteristics of jackfruit silage, using a randomized experimental design with factorial arrangement $3 \times 7$ (treatment $x$ day of opening) with two replications. Silos of PVC, $10 \mathrm{~cm}$ diameter $\mathrm{x} 40 \mathrm{~cm}$ in length, were used. The opening of the silos then assessing the chemical composition and silage fermentation occurred at 1, 3, 5, 7, 14, 28 and 56 days after ensiling. The dry matter (DM) and crude protein $(\mathrm{CP})$ were significantly highest $(\mathrm{P}<0.05)$ with the addition of $5 \%$ corn and $1 \%$ urea,
\end{abstract}

\footnotetext{
${ }^{1}$ Discente(s) de Doutorado em Ciência Animal e Pastagens, Escola Superior de Agricultura Luiz de Queiroz, ESALQ, Piracicaba, SP. E-mail: joaodorea@hotmail.com; gouveavin@usp.br

${ }^{2}$ Pesquisador da Embrapa Gado de Leite, Juiz de Fora, MG, Bolsista de Produtividade do CNPq. E-mail: luiz.gustavo@cnpgl. embrapa.br

${ }^{3}$ Discente de Doutorado em Zootecnia, Universidade Federal de Minas Gerais, UFMG, Belo Horizonte, MG. E-mail: axellfire@ gmail.com

${ }^{4}$ Discente de Doutorado em Zootecnia, Universidade Federal de Viçosa, UFV, Viçosa, MG. E-mail: timao22@hotmail.com

${ }^{5}$ Prof. do Dept $^{\circ}$ de Ciências Agrária e Ambientais, Universidade Estadual de Santa Cruz, UESC, Ilhéus, BA. Bolsista de Produtividade do CNPq. E-mail: augustog@uesc.br

${ }^{6}$ Discente de Doutorado em Solos e Nutrição de Plantas, Escola Superior de Agricultura Luiz de Queiroz, ESALQ, Piracicaba, SP. E-mail: andrefranco_agro@hotmail.com

* Autor para correspondência
} 
respectively. The $\mathrm{pH}$ found in all treatments was considered ideal for good quality silage. The addition of urea increased significantly $(\mathrm{P}<0.05)$ values of ammonia nitrogen $(\mathrm{N}-\mathrm{NH} 3 / \mathrm{NT})$. The addition of $1 \%$ urea worked as alkali in the cell wall of the ensiled material, shown by the reduction in levels of fibrous fractions. The jackfruit has a potential for conservation as silage and the use of corn and urea as additives enhances the fermentation and silage quality.

Key words: Additive, alternative food, Artocarpus heterophyllus, fermentation

\section{Introdução}

No Brasil, a jaca (Artocarpus heterophyllus) encontra-se bem disseminada, sendo mais comum na região litorânea que se estende do sul da Bahia até a Paraíba. Pereira et al. (2007) estudaram a utilização da jaca in natura na dieta de ruminantes e concluíram que este fruto pode ser uma boa alternativa na redução de custos com alimentos concentrados. Entretanto, como a produção de jaca concentra-se em determinado período do ano, fazse necessária a utilização de práticas que viabilizem seu armazenamento. A silagem pode ser uma opção, uma vez que é uma das práticas mais adotadas para conservação de alimentos para ruminantes.

Silagens bem conservadas devem apresentar teores de matéria seca superiores a 25\% (VILELA, 1984) e teores de carboidratos solúveis suficientes para garantirem processos de fermentação desejáveis. A infrutescência da jaca apresenta elevados teores de açúcares livres (RAHMAN et al., 1999).

Aditivos e inoculantes microbianos têm sido utilizados com o intuito de melhorar o padrão de fermentação e a qualidade da silagem por meio do favorecimento do desenvolvimento de bactérias produtoras de ácido lático e inibição das leveduras e bactérias do gênero Clostridium, podendo ainda melhorar a composição química do material ensilado.

O milhogrãotriturado (milho fubá), por apresentar elevado teor de matéria seca e constituir-se fonte de carboidratos, torna-se uma boa opção como aditivo para silagens. A ureia, outro potencial aditivo, pode propiciar aumento no teor de nitrogênio, impedir o aparecimento de fungos (CORRÊA, 2001), e, devido à sua propriedade alcalina, proporcionar a expansão da parede celular, aumentando a digestibilidade da silagem (HARBERS et al., 1982).

Esse trabalho teve como objetivo avaliar o potencial de conservação da infrutescência da jaca na forma de silagem e estudar os efeitos da inclusão de fubá de milho e uréia sobre a composição bromatológica e a dinâmica de fermentação da silagem.

\section{Material e Métodos}

O experimento foi conduzido no Laboratório de Nutrição Animal da Universidade Estadual de Santa Cruz (UESC), localizada no município de IlhéusBA.

$\mathrm{O}$ delineamento experimental utilizado foi $\mathrm{o}$ inteiramente casualizado em arranjo fatorial $3 \times 7$ (tratamentos e dias de abertura) com duas repetições. Os tratamentos foram: silagem de jaca (SJ); silagem de jaca $+5 \%$ de fubá de milho (SJFM) e silagem de jaca $+1 \%$ de uréia (SJU). A inclusão do fubá de milho e da uréia foram realizados com base na matéria natural da silagem de jaca.

Os frutos de jaca maduros foram obtidos em propriedades rurais da região sul da Bahia. Foram cortados longitudinalmente, picados em máquina picadeira estacionária e, em seguida, misturadas aos aditivos: fubá de milho e uréia, para posterior ensilagem.

Foram utilizados silos experimentais de PVC, com $10 \mathrm{~cm}$ de diâmetro e $40 \mathrm{~cm}$ de comprimento, adaptados com válvula tipo "Bunsen" e com capacidade para aproximadamente $3 \mathrm{~kg}$ de silagem. 
Os silos foram abertos com 1, 3, 5, 7, 14, 28 e 56 dias após a ensilagem. Com o auxílio de prensa hidráulica, o suco da silagem foi extraído e utilizado para determinação dos valores de $\mathrm{pH}$ em potenciômetro digital (RIBEIRO et al., 2007), e nitrogênio amoniacal como parte do nitrogênio total $\left(\mathrm{N}-\mathrm{NH}_{3} / \mathrm{NT}\right)$ conforme Bolsen et al. (1992). Parte da silagem foi amostrada e pré-seca em estufa de ventilação forçada a $60^{\circ} \mathrm{C}$ por 72 horas. Posteriormente foi realizado o processamento das amostras em moinho tipo Willey dotados de peneiras com crivos de $1 \mathrm{~mm}$. As variáveis analisadas foram: matéria seca (MS) segundo Silva e Queiroz (2002), proteína bruta (PB) pelo método de Kjedhal segundo a AOAC (1995); fibra detergente neutro (FDN) com a adição de amilase salivar termoestável; fibra detergente ácido (FDA) e lignina (LIG) conforme recomendações de Van Soest, Robertson e Lewis (1991). Determinou-se também o teor de hemicelulose conforme Silva e Queiroz (2002). A composição bromatológica do material antes da ensilagem está demonstrada na Tabela 1.

As perdas de matéria seca nas silagens sob as formas de gases, e a recuperação de matéria seca foram quantificadas por diferença de peso dos minisilos antes e após a ensilagem (ZANINE et al., 2010).

Tabela 1. Composição bromatológica da silagem de jaca (SJ); silagem de jaca acrescida de $5 \%$ de fubá de milho (SJFM) e silagem de jaca acrescida com $1 \%$ de uréia (SJU) antes da ensilagem.

\begin{tabular}{lrrr}
\hline & \multicolumn{3}{c}{ Tratamentos } \\
\cline { 2 - 4 } & SJ & SJFM & SJU \\
\hline Matéria Seca & 25,10 & 27,47 & 25,66 \\
Proteína Bruta & 8,39 & 9,69 & 17,11 \\
Fibra em detergente neutro & 27,70 & 33,43 & 23,84 \\
Fibra em detergente ácido & 19,39 & 21,52 & 15,65 \\
Hemicelulose & 12,80 & 11,92 & 8,19 \\
Lignina & 7,01 & 8,78 & 11,36 \\
\hline
\end{tabular}

Fonte: Elaboração dos autores.

Os dados foram interpretados por meio de análise de variância. As médias dos fatores qualitativos foram comparadas utilizando-se o teste Tukey ao nível de $5 \%$ de probabilidade e os dados quantitativos foram avaliados por estudos de regressão, no qual a escolha dos modelos baseou-se na significância dos parâmetros de regressão, testados pelo teste t $(\mathrm{P}<0,05)$ e nos valores dos coeficientes de determinação, utilizando-se o procedimento GLM do programa estatístico SAS (1999).

\section{Resultados e Discussão}

A inclusão de $5 \%$ de fubá de milho na ensilagem de jaca aumentou significativamente $(\mathrm{P}<0,05)$ o teor de MS da silagem, quando comparado a silagem de jaca e silagem de jaca $+1 \%$ de uréia (Tabela 2). Este aumento observado na silagem de jaca $+5 \%$ de fubá de milho está relacionado às características do aditivo utilizado, que possui elevado teor de MS e poder absorvente, reduzindo a umidade, proporcionando melhorias na fermentação e, ainda contribuindo com a redução ou eliminação de efluentes (WILKINSON, 1998; SILVA et al., 2007). Os teores de matéria encontrados para as três silagens estiveram próximos aos $25 \%$ sugeridos por Vilela (1984) como limite mínimo para processos fermentativos desejáveis.

A inclusão de fubá de milho assim como de uréia, proporcionaram aumentos significativos 
$(\mathrm{P}<0,05)$ no teor de $\mathrm{PB}$ do material ensilado (Tabela 2). Um aumento de 10\% no teor de PB da silagem foi obtido com a adição de $1 \%$ de uréia. Adições de uréia em 1\% da matéria verde (MV) são recomendadas para forrageiras como cana-deaçúcar para se obter bons resultados fermentativos (PEDROSO et al., 2007). Além disso, a uréia, sendo hidrolisada e produzindo amônia, pode resultar em efeito semelhante ao dos álcalis, expandindo a parede celular da planta após um período de armazenamento (HARBERS et al., 1982). Este efeito da amonização sobre a estrutura da fibra dos volumosos inclui a solubilização da hemicelulose e o aumento da digestão da celulose e da hemicelulose, em razão da expansão da fração fibrosa (JACKSON, 1977; KLOPFENSTEIN, 1978). A celulose se expande quando tratada com agentes alcalinos, o que reduz as ligações intermoleculares das pontes de hidrogênio, que ligam moléculas de celulose. Parte da lignina e sílica é dissolvida durante a amonização, e as ligações intermoleculares do tipo éster entre o ácido urônico da hemicelulose e da celulose são também rompidas (VAN SOEST, 1994). As reduções significativas $(\mathrm{P}<0,05)$ nos teores de FDN, FDA e LIG da silagem de jaca $+1 \%$ de uréia em relação à silagem de jaca e silagem de jaca $+5 \%$ de fubá de milho corroboram com estas suposições (Tabela 2).

Tabela 2. Teores de matéria seca (MS), proteína bruta (PB), fibra em detergente neutro (FDN), fibra em detergente ácido (FDA), hemicelulose (HEM), lignina (LIG) para os tratamentos: silagem de jaca (SJ); silagem de jaca acrescida de 5\% de fubá de milho (SJFM) e silagem de jaca acrescida de 1\% de uréia (SJU).

\begin{tabular}{lccccccc}
\hline & \multicolumn{3}{c}{ Tratamentos } & \multicolumn{3}{c}{ Valor P } & \multirow{2}{*}{ EPM $^{\mathbf{1}}$} \\
\cline { 2 - 6 } & SJ & SJFM & SJU & trat & dia & trat*dia & \\
\hline MS & $23,04 \mathrm{c}$ & $26,02 \mathrm{a}$ & $24,32 \mathrm{~b}$ & 0,0001 & 0,0003 & 0,9971 & 0,30 \\
$\mathrm{~PB}^{2}$ & $8,32 \mathrm{c}$ & $9,02 \mathrm{~b}$ & $18,23 \mathrm{a}$ & 0,0001 & 0,0331 & 0,2454 & 0,20 \\
$\mathrm{FDN}^{2}$ & $27,96 \mathrm{a}$ & $28,58 \mathrm{a}$ & $24,03 \mathrm{~b}$ & 0,0001 & 0,0009 & 0,4470 & 0,49 \\
$\mathrm{FDA}^{2}$ & $20,36 \mathrm{a}$ & $19,40 \mathrm{a}$ & $16,37 \mathrm{~b}$ & 0,0040 & 0,9159 & 0,8849 & 0,77 \\
$\mathrm{HEM}^{2}$ & $7,60 \mathrm{~b}$ & $9,19 \mathrm{a}$ & $7,11 \mathrm{~b}$ & 0,0009 & 0,0001 & 0,3932 & 0,34 \\
$\mathrm{LIG}^{2}$ & $10,33 \mathrm{a}$ & $10,44 \mathrm{a}$ & $6,74 \mathrm{~b}$ & 0,0001 & 0,0550 & 0,3112 & 0,49 \\
\hline
\end{tabular}

Médias nas mesmas linhas, seguidas de letras diferentes, diferem entre si $(\mathrm{P}<0,05)$ pelo teste Tukey, ${ }^{(1)}$ Erro padrão da média, ${ }^{(2)} \%$ de MS.

Fonte: Elaboração dos autores.

A adição de uréia à silagem elevou Ferreira et al. (2007) e Castro Neto et al. (2008), que significativamente $(\mathrm{P}<0,05)$ os valores de $\mathrm{N}-\mathrm{NH}_{3} /$ também observaram aumentos nos teores de $\mathrm{N}-\mathrm{NH}_{3}$ NT em relação às demais silagens (Tabela 3), o e PB quando foi utilizada uréia como aditivo na que corrobora com os resultados encontrados por ensilagem de cana-de-açúcar. 
Tabela 3. Valores de $\mathrm{pH}$, nitrogênio amoniacal (N-NH3/NT), recuperação de matéria seca (RMS), perdas por gases (PG) e densidade (DEN) para os tratamentos: silagem de jaca (SJ); silagem de jaca acrescida de 5\% de fubá de milho (SJFM) e silagem de jaca acrescida de $1 \%$ de uréia (SJU).

\begin{tabular}{lccccccc}
\hline & \multicolumn{3}{c}{ Tratamentos } & \multicolumn{3}{c}{ Valor P } & \multirow{2}{*}{ EPM } \\
\cline { 2 - 6 } & SJ & SJM & SJU & trat & dia & trat*dia & \\
\hline $\mathrm{pH}$ & $3,88 \mathrm{~b}$ & $3,83 \mathrm{c}$ & $3,95 \mathrm{a}$ & 0,0001 & 0,0001 & 0,0376 & 0,01 \\
$\mathrm{~N}^{-N H}{ }_{3}(\% \mathrm{NT})$ & $2,09 \mathrm{~b}$ & $2,09 \mathrm{~b}$ & $3,14 \mathrm{a}$ & 0,0001 & 0,0001 & 0,0089 & 0,04 \\
$\mathrm{RMS}^{2}$ & 90,62 & 93,02 & 93,24 & 0,2477 & 0,0001 & 0,9896 & 1,19 \\
$\mathrm{PG}^{2}$ & 5,61 & 4,37 & 6,30 & 0,2072 & 0,0072 & 0,5603 & 0,56 \\
$\mathrm{DEN}\left(\mathrm{kg} / \mathrm{m}^{3}\right)$ & 877,65 & 886,86 & 872,43 & 0,3159 & 0,7579 & 0,5816 & 6,61 \\
\hline
\end{tabular}

Médias nas mesmas linhas, seguidas de letras diferentes, diferem entre si $(\mathrm{P}<0,05)$ pelo teste Tukey, ${ }^{(1)}$ Erro padrão da média, ${ }^{(2)} \%$ de MS.

Fonte: Elaboração dos autores.

$\mathrm{O}$ aumento de $\mathrm{N}-\mathrm{NH}_{3}$ na silagem de jaca $+1 \%$ de uréia foi decorrente da ureólise (RYLEI, 1967), o que ocasionou maior capacidade tampão à silagem com aplicação de uréia, pois esta disponibiliza grande quantidade de nitrogênio na massa ensilada dificultando a diminuição do $\mathrm{pH}$, o que ocasionou aumento $(\mathrm{P}<0,05)$ no valor de $\mathrm{pH}$ para esta silagem quando comparado aos demais. Aumento no valor de $\mathrm{pH}$ e no teor de amônia foi observado por Bumbieris Junior et al. (2009), ao utilizarem a uréia como aditivo na ensilagem de grama estrela. Menores teores de $\mathrm{N}-\mathrm{NH}_{3} / \mathrm{NT}$ indicam menor intensidade de proteólise ocorrida na ensilagem, sendo característica de um processo de melhor qualidade. Segundo a classificação utilizada por Jayme et al.

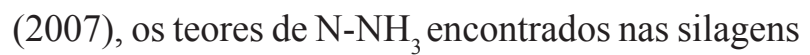
do presente trabalho estão caracterizados como muito boa por serem inferiores a $10 \%$.
Houve efeito de tratamentos sobre o $\mathrm{pH}$ das silagens. A silagem de jaca $+5 \%$ de fubá de milho apresentou menor valor de $\mathrm{pH}$, seguido da silagem de jaca e silagem de jaca $+1 \%$ de uréia (Tabela 3 ). A adição de fubá de milho, rico em carboidratos solúveis, pode ter favorecido a fermentação lática, explicando os menores valores de $\mathrm{pH}$. A jaca possui também elevado teor de carboidratos solúveis, em torno de 41,32\% (SANTOS et al., 2008), o que pode ter contribuído para a diminuição acentuada e rápida do $\mathrm{pH}$ nos primeiros dias de fermentação, garantido valores dentro da faixa considerada ideal por McDonald, Henderson e Heron (1991), que é de 3,8 a 4,2.

Houve interação $(\mathrm{P}<0,05)$ dos tratamentos com os dias de abertura dos silos, apenas para o $\mathrm{pH}$ e $\mathrm{N}-\mathrm{NH}_{3}$ (Tabela 3). A tabela 4 apresenta as equações de regressão para os valores de $\mathrm{pH}$ e $\mathrm{N}-\mathrm{NH}_{3}$, ilustradas na figura 1.

Tabela 4. Equações de regressão e coeficientes de determinação $\left(\mathrm{R}^{2}\right)$ para o valores de $\mathrm{pH}$ e nitrogênio amoniacal $\left(\mathrm{N}-\mathrm{NH}_{3} / \mathrm{NT}\right)$ da silagem de jaca (SJ); silagem de jaca acrescida de 5\% de fubá de milho (SJFM) e silagem de jaca acrescida de $1 \%$ de uréia (SJU) em função dos dias de abertura (dia).

\begin{tabular}{lccc}
\hline \multicolumn{1}{c}{ Variável: } & Tratamentos & Equações de regressão & $\mathbf{R}^{2}$ \\
\hline \multirow{2}{*}{$\mathrm{pH}$} & $\mathrm{SJ}$ & $\mathrm{y}=3,7595+0,6153 \mathrm{e}^{-0,3358^{*} \text { dia }}$ & 0,95 \\
& $\mathrm{SJFM}$ & $\mathrm{y}=3,6761+0,5032 \mathrm{e}^{-0,1844 * \text { dia }}$ & 0,93 \\
& $\mathrm{SJU}$ & $\mathrm{y}=3,8552+0,6199 \mathrm{e}^{-0,4265^{*} \text { dia }}$ & 0,98 \\
\hline \multirow{2}{*}{${\mathrm{N}-\mathrm{NH}_{3} / \mathrm{NT}}^{*}$} & $\mathrm{SJ}$ & $\mathrm{y}=2,7379-1,1554 \mathrm{e}^{-0,055 *^{*} \text { dia }}$ & 0,87 \\
& $\mathrm{SJFM}$ & $\mathrm{y}=2,1909-1,2723 \mathrm{e}^{-0,8055^{*} \text { dia }}$ & 0,72 \\
& $\mathrm{SJU}$ & $\mathrm{y}=3,6594-0,7720^{*} \mathrm{e}^{-0,0618^{*} \text { dia }}$ & 0,86 \\
\hline
\end{tabular}

Fonte: Elaboração dos autores. 
$\mathrm{O} \mathrm{pH}$ de todas as silagens foram reduzidos exponencialmente $(\mathrm{P}<0,05)$ em função dos dias de abertura (Figura 1) evidenciando o potencial de conservação da jaca na forma de silagem.

O comportamento exponencial do $\mathrm{pH}$ das silagens, diminuindo rapidamente nos primeiros dias e estabilizando-se ao longo do processo fermentativo em níveis adequados, demonstra um bom processo fermentativo, garantindo o mínimo de perdas do material ensilado. Este tipo de comportamento também foi encontrado em silagens de forrageiras tropicais por Sousa et al. 2006 e Pereira et al. 2006.

Figura 1. Valores de $\mathrm{pH}$ em função dos dias de abertura dos silos das silagens de jaca (SJ), jaca $+5 \%$ de fubá de milho (SJFM) e jaca $+1 \%$ de uréia (SJU).

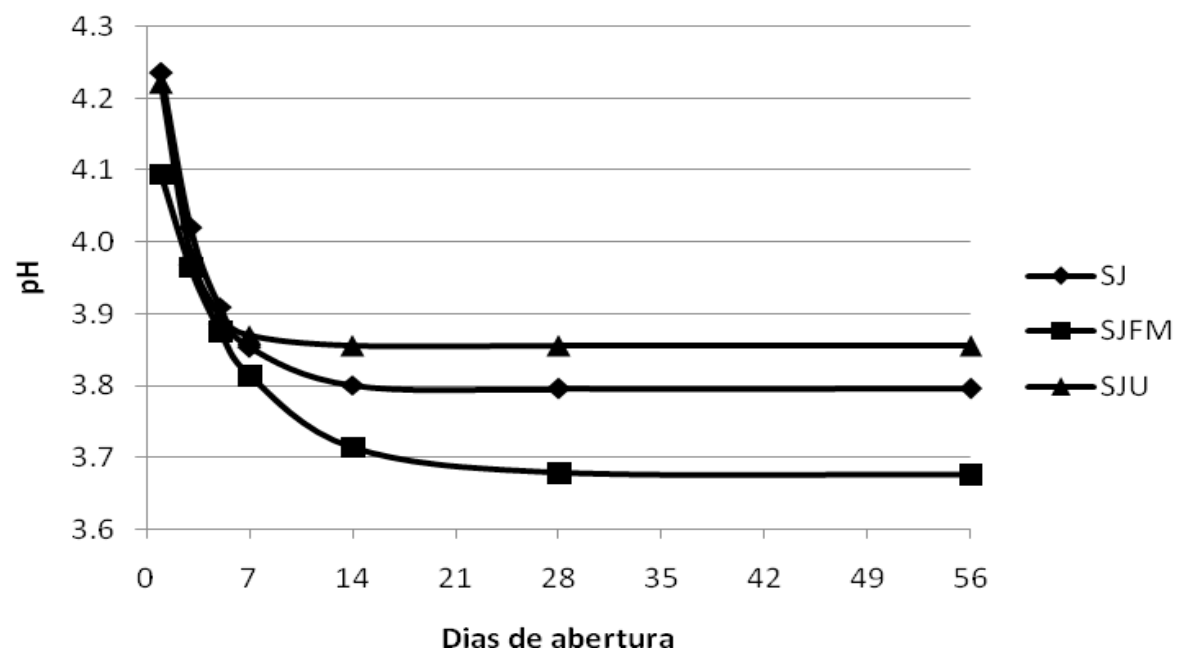

Fonte: Elaboração dos autores.

Os teores de N-NH3 das silagens apresentaram comportamento exponencial, aumentando $(\mathrm{P}<0,05)$ em função dos dias de abertura dos silos (Figura 2). A silagem de jaca $+5 \%$ de fubá de milho apresentou o melhor perfil assintótico da curva, refletindo uma fermentação de qualidade, embasada por valores adequados de $\mathrm{pH}$ e elevada recuperação de matéria seca que indica baixas perdas na fermentação. $\mathrm{O}$ comportamento da silagem de jaca $+5 \%$ de fubá de milho demonstrou maior redução na proteólise em relação à silagem de jaca e silagem de jaca $+1 \%$ de uréia. Apesar do valor de PB antes da ensilagem (Tabela 1) estar próximo ao teor de PB após a ensilagem, em todos os tratamentos, é possível perceber que parte do nitrogênio contabilizado como PB é nitrogênio oriundo da amônia. Neste caso, como o teor de $\mathrm{N}_{-} \mathrm{NH}_{3}$ foi baixo, principalmente na silagem de jaca $+5 \%$ de fubá de milho, o teor de PB expresso após a ensilagem é composto de reduzida participação de $\mathrm{N}_{-} \mathrm{NH}_{3}$, ao contrário do que é observado com o tratamento silagem de jaca $+1 \%$ de uréia . 
Figura 2. Valores de nitrogênio amoniacal como parte do nitrogênio total (N-NH $\left.\mathrm{N}_{3} / \mathrm{NT}\right)$ em função dos dias de abertura dos silos das silagens de jaca (SJ), jaca $+5 \%$ de fubá de milho (SJFM) e jaca $+1 \%$ de uréia (SJU).

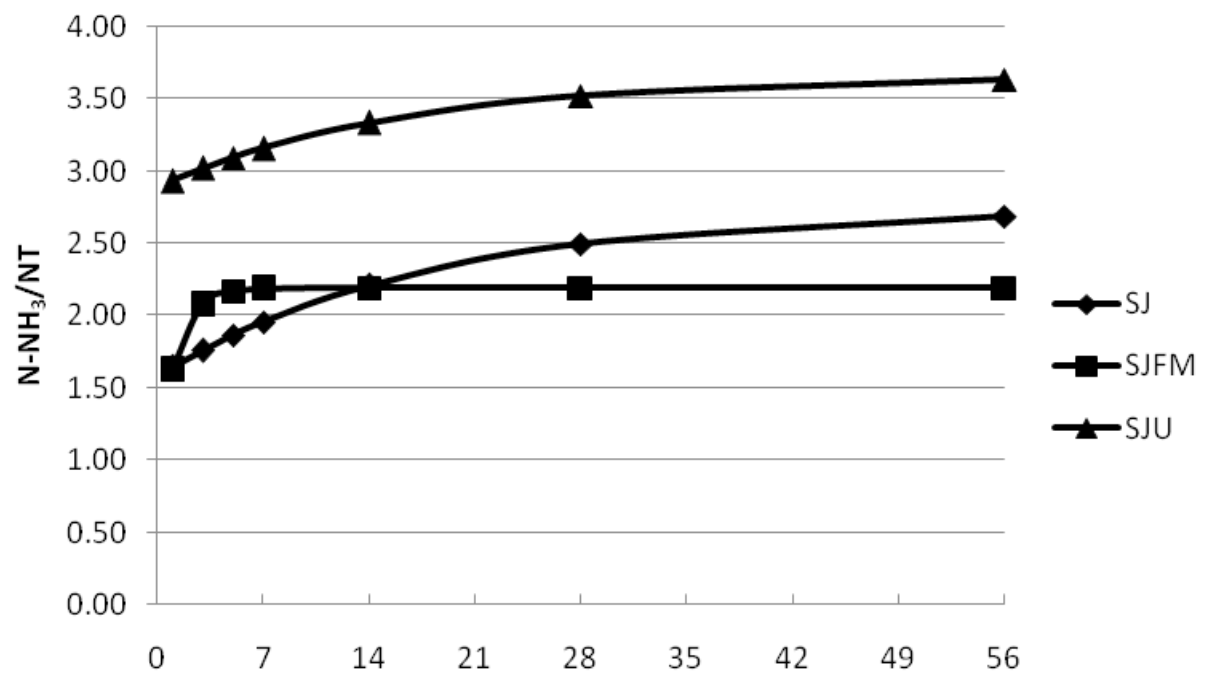

Dias de abertura

Fonte: Elaboração dos autores.

Em nenhum momento durante os dias de abertura dos silos os teores de $\mathrm{N}_{-} \mathrm{NH}_{3}$ estiveram acima de $15 \%$, o que poderia indicar fermentação indesejável em silagens de gramíneas, conforme descrito por Mahanna (1993).

Não houve efeito $(\mathrm{P}>0,05)$ para densidade, recuperação de matéria seca e perdas por gases. $\mathrm{O}$ valores encontrados no presente trabalho foram baixos e semelhantes aos encontrados por Santos et al. (2008), que utilizaram a jaca como aditivo na ensilagem de capim elefante. Oliveira et al. (2010), obtiveram valores de perdas por gases na silagem de sorgo próximos aos encontrados no presente estudo.

As perdas de matéria seca em silagens se dão principalmente pelo consumo de carboidratos solúveis, via processo respiratório da planta, de microorganismos aeróbios ou pelo processo fermentativo. Esse fato ocorreu de forma leniente nas silagens estudadas, evidenciado pela elevada recuperação da matéria seca nas três silagens avaliadas.

Os resultados apresentados comprovam o bom potencial para conservação da jaca na forma de silagem, técnica que auxilia a racionalização de sua utilização na alimentação animal, uma vez que sua produção apresenta-se bastante concentrada em poucos meses do ano.

\section{Conclusões}

A jaca apresenta potencial para ser conservada na forma de silagem. A utilização de milho e uréia como aditivos melhoram o perfil fermentativo e a qualidade da silagem de jaca.

\section{Referências}

ASSOCIATION OF OFFICIAL ANALYTICAL CHEMISTS - AOAC. Official methods of analysis. 16. ed. Washington, DC: AOAC, 1995.

BOLSEN, K. K.; LIN, C.; BRENT, B. E.; FEYIERHERM, A. M.; URBAN, J. E.; AIMUTIS, W. R. Effect of silage additives on the microbial succession and fermentation process of alfalfa and corn silages. Journal of Dairy Science, Champaign, v. 75, n. 11, p. 3066 - 3083, 1992.

BUMBIERIS JUNIOR, V. H.; JOBIM, C. C.; CALIXTO JUNIOR, M.; CECATO, U. Composição química e digestibilidade em ovinos da grama estrela ensilada com diferentes aditivos. Ciência Agrotécnica, Lavras, v. 33, n. 
5, p. 1408 - 1414, 2009

CASTRO NETO, A. G.; MOLINA, L. R.; GONÇALVES, L. C.; JAYME, C. G. Parâmetros de fermentação de silagens de cana-de-açúcar submetidas a diferentes tratamentos. Arquivos Brasileiro de Medicina Veterinária e Zootecnia, Belo Horizonte, v. 60, n. 5, p. 1150 - 1156, 2008.

CORRÊA, C. E. S. Silagem de milho ou cana-de-açúcar e o efeito da textura do grão de milho no desempenho de vacas holandesas. 2001. Tese (Doutorado em Zootecnia) - Curso de Pós-Graduação em Zootecnia. Universidade Federal de Lavras, Lavras.

FERREIRA, D. A.; GONÇALVES, L. C.; MOLINA, L. R.; CASTRO NETO, A. G.; TOMICH, T. R. Características de fermentação da silagem de cana-deaçúcar tratada com uréia, zeólita, inoculante bacteriano e inoculante bacteriano/enzimático. Arquivos Brasileiro de Medicina Veterinária e Zootecnia, Belo Horizonte, v. 59, n. 2, p. 423 - 433, 2007.

HARBERS, L. H.; KREITNER, G. L.; DAVIS, G. V.; RASMUSSEN, M. A.; CORAH, L. R. Ruminal digestion of ammonium hydroxide-treated wheat straw observed by scanning electron microscopy. Journal of Animal Science, Champaign, v. 54, n. 6, p. 1309-1319, 1982.

JACKSON, M. G. The alkali treatment on straws. Animal Feed Science and Technology, Amsterdam, v. 2, n. 2, p. 105-130, 1977.

JAYME, D. G.; GONÇALVES, L. C.; RODRIGUES, J. A. S.; PIRES, D. A. A.; GUIMARÃES JÚNIOR, R.; RODRIGUEZ, N. M.; BORGES, I.; BORGES, A. L. C. C.; SALIBA, E. O. S.; JAYME, C. G. Qualidade das silagens de genótipos de girassol (Helianthus annuus) confeiteiros e produtores de óleo. Arquivos Brasileiro de Medicina Veterinária e Zootecnia, Belo Horizonte, v. 59, n. 5, p. 1287-1293, 2007.

KLOPFENSTEIN, T. J. Chemical treatment of crops residues. Journal of Animal Science, Champaign, v. 46, n. 3, p. 841-848, 1978.

MAHANNA, B. Troubleshooting silages problems. In: STATE APPLIED NUTRITION CONFERENCE, 4., 1993, West Des Moines. Summary... West Des Moines: Pioneer Hi-bred International Inc., 1993. p. 1-21.

McDONALD, P.; HENDERSON, A. R.; HERON, S. J. E. The biochemistry of silage 2. ed. Marlow: Chalcombe Publications, 1991.226 p.

OLIVEIRA, L. B.; PIRES, A. J. P.; CARVALHO, G. G. P.; RIBEIRO, L. S. O.; ALMIDA, V. V.; PEIXOTO, C. A. M. Perdas e valor nutritivo de silagens de milho, sorgosudão, sorgo forrageiro e girassol. Revista Brasileira de Zootecnia, Viçosa, MG, v. 39, n. 1, p. 61-67, 2010.
PEDROSO, A. F.; NUSSIO, L. G.; LOURES, D. R. S.; PAZIANI, S. F.; IGARASI, M. S.; COELHO, R. M.; HORII, J.; RODRIGUES, A. A. Efeito do tratamento com aditivos químicos e inoculantes bacterianos nas perdas e na qualidade de silagens de cana-de-açúcar. Revista Brasileira de Zootecnia, Viçosa, MG, v. 36, n. 3, p. 558-564, 2007.

PEREIRA, D. H.; PEREIRA, O. G.; VALADARES FILHO, S. C.; GARCIA, R.; OLIVEIRA, A. P.; MARTINS, F. H.; VIANA, V. Consumo, digestibilidade dos nutrientes e desempenho de bovinos de corte recebendo silagem de sorgo (Sorghum bicolor (L.) Moench) e diferentes proporções de concentrado. Revista Brasileira de Zootecnia, Viçosa, MG, v. 35, n. 1, p. 1018, 2006.

PEREIRA, L. G. R.; MAURÍCIO, R. M.;AZEVÊDO, J.A. G.; OLIVEIRA, L. S.; BARREIROS, D. C.; FERREIRA, A. L.; BRANDÃO, L. G. N.; FIGUEIREDO, M. P. Composição bromatológica e cinética de fermentação ruminal in vitro da jaca dura e mole (Artocarpus heterophyllus). Livestock Research Rural Development, Cali, v. 19, n. 45, p. 7-12, 2007.

RAHMAN, M. A.; NAHAR, N.; JABBAR, M. A.; MOSIHUZZAMAN, M. Variation of carbohydrate composition of two forms of fruit from jack tree (Artocarpus heterophyllus L.) with maturity and climatic conditions. Food Chemistry, London, v. 65, n. 1, p. 9197, 1999.

RIBEIRO, C. G. M.; GONÇALVES, L. C.; RODRIGUES, J. A. S.; RODRIGUEZ, N. M.; BORGES, I.; BORGES, A. L. C. C.; SAliBA, E. O. S.; CASTRO, G. H. F.; RIBEIRO JUNIOR, G. O. Padrão de fermentação da silagem de cinco genótipos de sorgo. Arquivos Brasileiro de Medicina Veterinária e Zootecnia, Belo Horizonte, v. 59, n. 6, p. 1531-1537, 2007.

RYLEI, J. W. Silage with urea. In: BRIGGS, M. H. (Ed.). Protein supplement. Oxford: Pergamon Press, 1967. p. 391-410.

SANTOS, E. M.; ZANINE, A. M.; DANTAS, P. A. S.; DÓREA, J. R. R.; SILVA, T. C.; PEREIRA, O. G.; LANA, R. P.; COSTA, R. G. Composição bromatológica, perdas e perfil fermentativo de silagens de capim-elefante com níveis de inclusão de jaca. Revista Brasileira de Saúde e Produção Animal, Salvador, BA, v. 9, n. 1, p. 64-73, 2008.

SILVA, D. J.; QUEIROZ, A. C. Análise de alimentos: métodos químicos e biológicos. 3. ed. Viçosa, MG: UFV, Imprensa Universitária, 2002. 235 p.

SILVA, F. F.; AGUIAR, M. S. M. A.; VElOSO, C. M.; PIRES, A. J. V.; BONOMO, P.; DUTRA, G. S.; 
ALMEIDA, V. S.; CARVALHO, G. G. P.; SILVA, R. R.; DIAS, A. M.; ÍTAVO, L. C. V. Bagaço de mandioca na ensilagem do capim-elefante: qualidade das silagens e digestibilidade dos nutrientes. Arquivos Brasileiro de Medicina Veterinária e Zootecnia, Belo Horizonte, v. 59, n. 3, p. 719-729, 2007.

SOUSA, L. O.; SANTOS, E. M.; PENTEADO, D. C. S.; CARVALHO, G. G. P.; OLIVEIRA, J. S.; PEREIRA, O. G. Composição bromatológica de silagem de capimmombaça inoculada com Lactobacilus plantarum da microbiota epifítica. In: CONGRESSO NACIONAL DE ZOOTECNIA, 6., 2006, Recife. Anais... Recife: Universidade Federal Rural de Pernambuco, 2006. p. 145-146.

STATISTICALANALYSES SYSTEM - SAS. SAS user's guide: Statistics. Cary: SAS Institute, 1999. 983 p.

VAN SOEST, P. J. Nutritional ecology of the ruminant. 2. ed. Ithaca: Cornell University Press, 1994. 476 p.
VAN SOEST, P. J.; ROBERTSON, J. B.; LEWIS, B. A. Methods for dietary fiber, neutral detergent, and nonstarch polysaccharides in relation to animal nutrition. Journal of Dairy Science, Champaign, v. 74, n. 10, p. 3583-3597, 1991.

VILELA, D. Aditivos para ensilagem. Juiz de Fora: Embrapa/CNPGL, 1984. 15 p. (Circular técnico, 21).

WILKINSON, J. M. Additives for ensiled temperate forage crops. In: REUNIÃO ANUAL DA SOCIEDADE BRASILEIRA DE ZOOTECNIA, 35., 1998, Botucatu. Anais... Botucatu: Sociedade Brasileira de Zootecnia, 1998. p. 73-108.

ZANINE, A. M.; SANTOS, E. M.; DÓREA, J. R. R.; DANTAS, P. A. S.; SILVA, T. C.; PEREIRA, O. G. Evaluation of elephant grass silage with the addition of cassava scrapings. Revista Brasileira de Zootecnia, Viçosa, MG, v. 39, n. 12, p. 2611 - 2616, 2010. 
